\title{
Inflammatory Myelopathy Presenting as a Cystic Intramedullary Spinal Cord Lesion
}

\author{
B.I. Tranmer, T.A. Gray, W.J. Horsey, C.G. Gonsalves
}

\begin{abstract}
A case of subacute progressive spinal tetraparesis had myelographic evidence of cervical spinal cord swelling and a delayed metrizamide computed tomographic myelogram (MCTM) suggested cavitation within the swollen spinal cord. Surgical exploration of the cervical cord revealed inflammatory changes only. No syrinx or intramedullary tumour was found. The accumulation of metrizamide within the spinal cord, as demonstrated by MCTM, did not respresent a syrinx or a cystic tumour, but more likely an area of inflammation. Because inflammatory myelopathy may simulate an intramedullary tumor or syrinx, careful analysis of all clinical and radiological information is necessary to help make a correct diagnosis.
\end{abstract}

RÉSUMÉ: Dans un cas de quadriparésie progressive subaigüe, la myélographie a révélé un élargissement de la moëlle cervicale, et la tomographie axiale une cavité intraspinale étagée correspondante. L'exploration chirurgicale n'a permis de documenter que des changements inflammatoires. Contrairement à ce que l'accumulation segmentaire du Metrizamide avait laissé suspecter, ni syrinx, ni tumeur intraspinale n'a été retrouvé.

La myélopathie inflammatoire pouvant simuler une tumeur ou une cavité syringomyélique, son diagnostic présuppose une analyse encore plus rigoureuse des données cliniques et radiologiques.

Can. J. Neurol. Sci. 1984; 11:399.401

In the past decade, metrizamide myelography has become an important procedure for diagnosing spinal cord abnormalities. Recently, better definition of cord pathology has been obtained by metrizamide computed tomographic myelography (MCTM). In this procedure the spinal cord is scanned by computed tomography following an intrathecal injection of metrizamide.

A fusiform swelling of the spinal cord, as demonstrated by myelography, usually is associated with an intramedullary tumour or syrinx. Computed tomography may help distinguish tumour from syrinx. Following an intravenous injection of contrast agent, a spinal cord tumour should enhance on the CT scan and a syrinx should remain as a low density lesion. When metrizamide is injected intrathecally, a syrinx will gradually fill with metrizamide and will appear as a high density lesion within the spinal cord on the metrizamide computed tomographic myelogram. However, a cystic spinal cord tumour rarely may also accumulate metrizamide.

We have recently managed a patient with an inflammatory myelopathy whose MCTM revealed a metrizamide-filled lesion within a swollen spinal cord. This was thought to represent a syrinx or a cystic tumour (Bonafe et al., 1980; Winkler and Sackett, 1980) and she underwent exploration of her cervical spinal cord.

\section{Case History}

A 31 year old Portugese woman was admitted to St. Michael's Hospital on October 6, 1982 for investigation of right arm and leg weakness and bilateral paresthesia. She was in good health until two months earlier when she developed a burning neck pain over a two day period. This burning pain radiated into both shoulders with neck flexion. One week later, she developed numbness in both arms and weakness of the right arm. Over the next week, the numbness extended into the right trunk and leg, and the right leg became weak. A myelogram, performed in another hospital, was reported to be normal. However, the motor and sensory symptoms progressed during the next two weeks and she was admitted to hospital for further investigation. She complained of severe burning neck pain which radiated as shocks into the right arm and hand. She found walking difficult and all four extremities felt numb.

She had malaria and rheumatic fever many years earlier and cholecystectomy, hysterectomy and splenectomy had been performed during the last few years.

Physical examination revealed findings of a cervical cord lesion. The cranial nerve examination was normal. She had severe weakness of her proximal right upper extremity and moderate weakness of that hand. The right leg was mildly weak. There was impaired pain and touch sensation in the right upper extremity, trunk and lower extremity. The lower limbs were hyper reflexic and Babinski signs were present bilaterally. During the next five days, the right upper extremity developed a flaccid paralysis, the left hand became paretic and she became bedridden

From the Division of Neurology, Neurosurgery and Neuroradiology. St. Michael's Hospital and University of Toronto.

Received December 13, 1983. Accepted in revised form May 11, 1984.

Reprint requests to: Dr. T.A. Gray, St. Michael's Hospital, Toronto, Ontario. 
because of proximal leg weakness bilaterally. Because of urinary retention, catheterization was necessary.

A pantopaque myelogram showed the cervical spinal cord to have fusiform swelling from $\mathrm{C} 2$ to $\mathrm{C} 6$ suggesting the presence of an intramedullary lesion (figure 1). In the C4-C5 region, the cord appeared to occupy more than 80 per cent of the spinal canal. Cerebrospinal fluid analysis showed 6 lymphocytes/ml, a slightly elevated protein content $(5.3 \mathrm{mg} / \mathrm{l})$ and a normal sugar value. The gammaglobulin content was elevated.

A metrizamide computed tomographic myelogram was performed using $10 \mathrm{ml}(170 \mathrm{mg}$ iodine $/ \mathrm{ml})$ metrizamide. Delayed films of 8 and 12 hours showed an abnormally fat spinal cord from $\mathrm{C} 2$ to $\mathrm{C} 6$ and, in addition, revealed accumulation of metrizamide with the cord in the C5.C6 region (figure 2). An intramedullary lesion, either syrinx or cystic tumour, was diagnosed.

The cervical spinal cord was explored after performing an extensive cervical laminectomy. When the dura was opened, the cord appeared discoloured and swollen from $\mathrm{C} 2$ to $\mathrm{C} 7$, but no specific lesion was seen on its surface. Multiple needle aspirations yielded no fluid and biopsies revealed only inflammatory changes.

During the postoperative period, her neurological condition steadily improved. Because we suspected demyelination after the biopsies were reported negative for neoplasia, she was given prednisone $60 \mathrm{mg}$ daily. Within three weeks she was free of neck pain, walking without aid and completely off steroids. The right hand had useful function and bladder function was normal.

Improvement continued for another six days, when she noticed that her walking had deteriorated, her right hand was clumsy, and urinary retention returned. Examination revealed that the power in the right upper limb and both legs had deteriorated. Cerebropsinal fluid analysis showed a mild elevation of lymphocytes and protein. Recurrence of the inflammatory myelitis was suspected and steroids were again administered. As before, marked improvement occurred over a 3-4 week period.

The clinical history and findings were felt to be compatible with inflammatory myelopathy, most likely secondary to demyelination of multiple sclerosis.

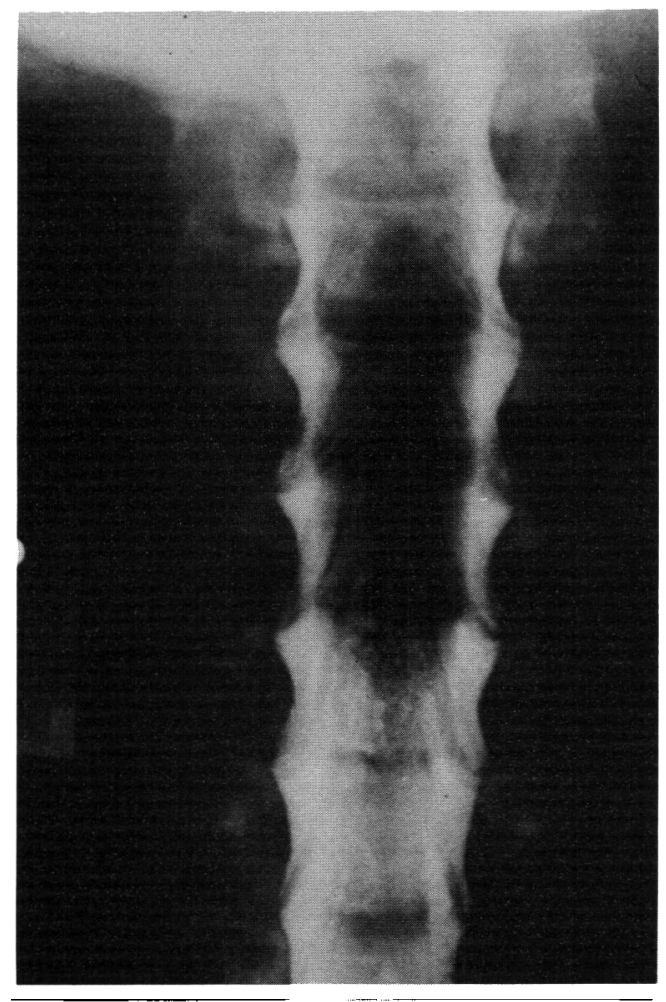

Figure 1 - Pantopaque myelogram. AP view showing widening of cervical spinal cord from C-2 - C-6 level. This fusiform swelling suggests the presence of an intramedullary mass.

\section{Discussion}

Metrizamide computed tomographic myelography was introduced by DiChiro and Schellinger (1976). This procedure provides important visualization of the morphology of the spinal cord and allows dynamic study of cerebrospinal fluid pathways. When metrizamide myelography demonstrates a fusiform swelling of the spinal cord, the diagnosis of an intramedullary mass such as a tumour or syrinx should be suspected. Although the specific diagnosis may remain uncertain until the lesion is surgically explored, a number of radiological distinguishing features may be seen. The "collapsing cord sign" on myelography is pathognomonic of syringomyelia. A contrast-enchanced CT-scan may demonstrate tumour tissue, but a syrinx will remain a low density lesion. A MCTM will further help to distinguish syrinx from tumour. After metrizamide is injected into the subarachnoid space, metrizamide will accumulate in the cyst during the immediate scan or later on a delayed scan. It must be remembered, however, that a cyst occasionally may be associated with an intramedullary tumour and rarely may also accumulate metrizamide.

Although syrinx and tumour are the most common causes of spinal cord swelling, a recent report described three cases of inflammatory myelopathy secondary to multiple sclerosis that had myelographic evidence of spinal cord swelling (Feasby et al., 1981). The authors suggest that other investigations such as cerebrospinal fluid protein electrophoresis, evoked potentials, and CT scanning may be necessary to make a correct diagnosis of cord swelling.

Opacification of a well defined, initially low density region in a swollen spinal cord following an intrathecal injection of metrizamide is good evidence of syringomyelia. The mechanism by which the metrizamide fills the syrinx is poorly understood.

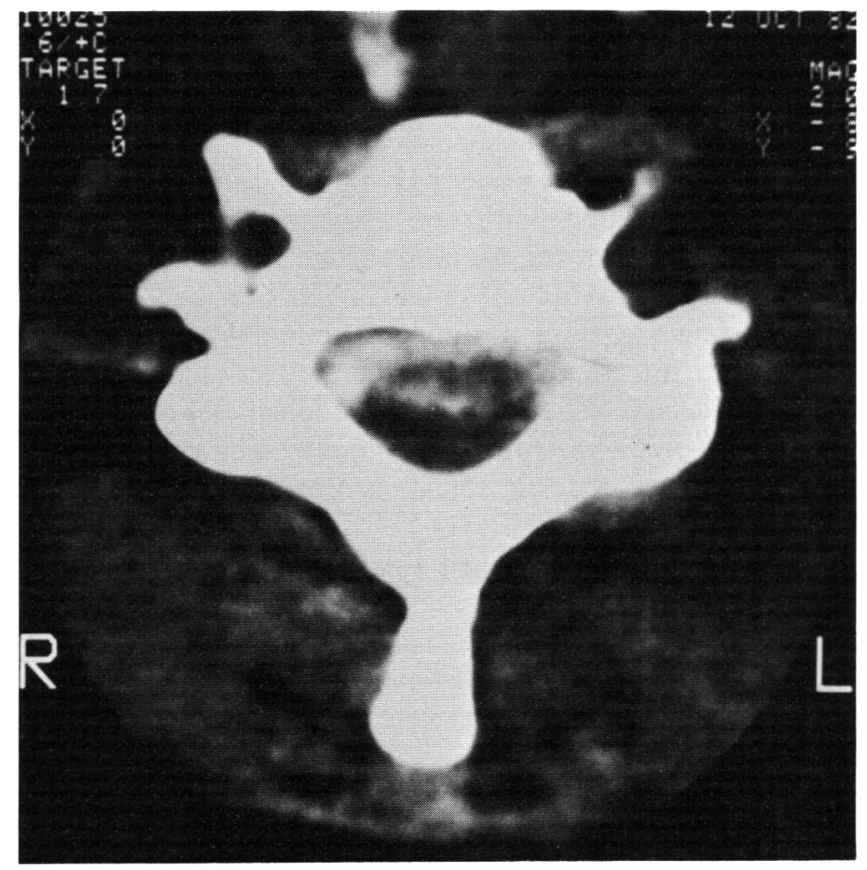

Figure 2-Metrizamide computed tomographic myelogram (delayed 8 hours). The spinal cord is abnormally wide at this level (C5) and shows an accumulation of metrizamide within the cord. 
In the past, it was felt that if the cyst opacified immediately, the cyst was in direct communication with the subarachnoid space. If the cyst opacified several hours later, it was assumed that the metrizamide reached the cyst indirectly via the fourth ventricle. Recent evidence suggests that the metrizamide may in fact diffuse directly through the spinal cord from the subarachnoid space and collect in the syrinx. Penetration of metrizamide into the brain parenchyma after subarachnoid injection has been demonstrated (Drayer and Rosenbaum, 1977; Goldman, 1973). The distribution of metrizamide in the brain has been shown by Goldman to be primarily extracellular (Goldman, 1973). Dubois demonstrated that the metrizamide also crosses the cerebrospinal fluid - spinal cord barrier to enter the parenchyma of the spinal cord (Dubois et al., 1981). The metrizamide progressively increased the density of the cervical spinal cord of dogs over several hours, and maximal enhancement of the cord was delayed allowing time for metrizamide diffusion from the subarachnoid space into the cord. Isherwood observed a $20 \mathrm{~h}$ (Hounsfield unit) increase of attenuation value in the spinal cord of humans in the first hour after subarachnoid injection of metrizamide (Isherwood et al., 1977). This was followed by progressive diminution of cord attenuation values over the subsequent five hours. Some cord attenuation values peaked later at three to six hours after the injection.

Barnett studied nine patients with syringomyelia with delayed metrizamide computed tomography (Barnett et al., 1980). Subarachnoid injection of metrizamide demonstrated cord dilatation in six patients and cord atrophy in three patients. Delayed CT scans showed contrast opacification of the syrinx in all patients.

It was felt that these observations supported the theory that fluid in some intramedullary cavities arise from the subarachnoid space and passes directly into the cavity through the spinal cord.

Our patient suffered inflammatory myelopathy of the cervical cord and yet the MCTM demonstrated well defined areas of delayed metrizamide accumulation within the spinal cord parenchyma suggesting cavitation. Current evidence suggests that metrizamide penetrates brain and spinal cord and is distributed through the extracellular space. It is possible that metrizamide may collect in areas of inflammation within the oedematous extra cellular space. This localized accumulation of metrizamide would give the impression of a cyst-like structure in the spinal cord on the MCTM.

Differentiating inflammatory myelopathy from syringomyelia and intramedullary spinal cord tumour can be quite difficult at times and other diagnostic measures such as CSF analysis, visual evoked potentials and CT scan (head) may be helpful. Multiple sclerosis patients with this condition may also have positive oligoclonal banding on CSF analysis, abnormal visual evoked potentials and cerebral plaques of demyelination on a CT scan (head). A CT scan may also demonstrate hydrocephalus or an Arnold-Chiari malformation in the patient with a syrinx, or spinal cord tumours. However, even after reviewing all clinical features, radiological data, and laboratory results, exploratory spinal cord surgery may be necessary to make a definitive diagnosis.

\section{REFERENCES}

Barnett HJM, Fox A, Vinuela F, Peerless SJ (1980) Delayed metrizamide CT observations in syringomyelia. (Abstr) Ann Neurol., 8: 116.

Bonafe A, Manelfe C, Espagno J, Guirand B, Rascol A (1980) Evaluation of syringomyelia with metrizamide computed tomographic myelography. J. Comput. Assist. Tomogr., 4: 792-802.

DiChiro G, Schellinger CS (1976) Computed tomography of spinal cord after lumbar intrathecal introduction of metrizamide. (Computed Assisted Myelography). Radiology, 20: 101-104.

Drayer B, Rosenbaum A (1977) Metrizamide brain penetrance. Acta. Radiol. (Suppl.) 355: 280-293.

Dubois P, Drayer B, Sage M, Osborne D, Heinz E (1981) Intramedullary penetrance of metrizamide in the dog spinal cord. Am. J. Neurorad., 2: 313-317.

Feasby T, Paty D, Ebers G, Fox A (1981) Spinal cord swelling in multiple sclerosis. Can. J. Neur. Sci., 8: 151-153.

Goldman K (1973) Distribution and retention of I-125 metrizamide after intravenous and suboccipital injection of rabbit, rat and cat. Acta. Radiol. 335: (Suppl.) 300-311.

Isherwood I, Fawcett RA, Forbes W (1977) Computer tomography of the spinal canal using metrizamide. Acta. Radiol. (Stockh.), 355: (Suppl.) 229-305.

Winkler S, Sackett J (1980) Explanation of metrizamide brain penetrance: A review. J. Comput. Assist. Tomogr., 4: 191-193. 